\title{
Home Access: Providing Computers to Families via a National Strategy
}

\author{
Nicola Yelland ${ }^{1}$, Greg Neal ${ }^{2}$, and Eva Dakich ${ }^{2}$ \\ ${ }^{1}$ Hong Kong Institute of Education, Faculty of Education Studies. 10 Lo Ping Road, \\ Tai Po, Hong Kong SAR \\ yellandaied.edu.hk \\ ${ }^{2}$ Victoria University, School of Education, Footscray Park Campus, Victoria, Australia \\ \{Greg.neal, eva.dakich\}@vu.edu.au
}

\begin{abstract}
In this paper we discuss the role of new technologies, and computers in particular, in lives of families in Australia. We report on part of a project that provided children families with computers and connection to the Internet. There is an increasing awareness that living in the 21 st century involves using and interacting with a range of new technologies, also referred to as information and communications technologies (ICT). However, for many children and their families this is not possible because they do not have the capacity to purchase them. The Tech Packs Project (The Smith Family, 2007) grew out of the Computer for Every Child Project which was an attempt to start to bridge the 'digital divide' by providing computers so that a group of families in the targeted locations of large metropolitan cities could participate in the Information Age. The families involved were those whose personal resources did not afford them the opportunity to purchase new technologies, especially computers We surveyed the families members to determine the extent of their use of any technologies before and after receiving the computer and initiated focus groups to find out the ways in which having a computer created contexts for them to become more proficient in the use of ICT In this paper we will present the findings from both the survey and focus group data that we have collected.
\end{abstract}

Keywords: Home access, digital divide, computers for learning.

\section{Introduction}

The Millennials [1], that is those children born post 1985, play around in digital spaces and communicate on a daily basis with peers, family and acquaintances for a variety of purposes using many devices. A large number of homes have a variety of media options that include; TVs, mobile phones, computers, ipods, mp3 players, DVD machines, digital cameras, interactive toys and games and video game consoles and mobile devices. For many years now the Kaiser Family Foundation have conducted a surveys pertaining to the media use among children and teens in the US [2]. The latest (third) report states that since the last survey (2004) there has been a major 
increase in use of new media that is mainly attributed to the ready access to mobile devices. For example, they report that in the past 5 years there has been a large increase in mobile phone ownership, from $39 \%$ to $66 \%$, and the increase in ipod ownership has soared from $18 \%$ to $76 \%$. What is also apparent is that mobile phones for example are more than for talking on. In fact more young people spend time listening to music, playing games and watching TV on their mobile phones (a total of :49 daily) than they spend talking on them (:33). The most salient finding was that "The amount of time young people spend with media has grown to where it's even more than a full-time work week" (p.1). In fact the findings reported in their documentation revealed that "Eight to eighteen year olds spend more time with media than in any other activity... an average of more than 71/2 hours a day, seven days a week" (p.1). This was an increase of one hour a day from their previous report five years prior to this survey. It represents a greater amount of time than many adults spend in full time employment, and they do it seven days a week not for five days. The report informs us that:

In the last five years, home Internet access has expanded from $74 \%$ to $84 \%$ among young people; the proportion with a laptop has grown from just under $12 \%$ to $29 \%$; and Internet access in the bedroom jumped from $20 \%$ to $33 \%$. The quality of Internet access has improved as well, with high-speed access increasing from $31 \%$ to $59 \%$ (p.3).

High speed Internet access and new applications have meant that the ways in which the Internet are used by young people have changed significantly. The most popular computer activities are those of social networking and video sites like YouTube. Such sites were not widely available in 2004 - but now account for an average of :37 of their daily media time.

There is some space in the report to discuss demographic aspects of the data but this is confined to age, gender, race and parental educational levels. There is no specific consideration of socio economic status or parental income levels. Data shows that media use increases considerably in the years between 11 and 14 years of age. Girls spend more time than boys in social network contexts, listening to music and reading. Boys spend more time playing video and computer games and looking at YouTube. Black and Hispanic children spend more time with media than white children but this seems to be because they spend so much more time watching TV. They consume 13 and 12:59 hours (Black and Hispanic children respectively) while White kids consume 8:36 hours.

Yet there remain children and families who are not able to participate in the socalled 'digital revolution' for a variety of reasons that tend to be closely aligned to social and economic circumstances. Studies conducted regarding the links between social and digital engagement, especially with reference to Internet use, increasingly show that those individuals who have access to ICT, generally come from families that have more schooling, higher incomes, and high status occupations. In discussing digital and social advantage, Helsper [3] noted that "those who are most deprived socially are also least likely to have access to digital resources such as online services" (p.9). Further, Helsper reported that when those from these demographic groups do participate in digital activity, it tends to be at the basic level and involve information seeking, obtaining leisure information, making purchases on line and for individual communication with families and friends at a distance. In contrast, Helsper 
indicated that the advanced levels of activity characterized by social networking and civic engagement that allow participants to interact beyond their immediate networks, for example, are only conducted by $8 \%$ of the population. This then reinforces a gap since this qualitative difference in use enables those with more advanced technologies and applications to participate in activities that facilitate and extend their capabilities in cyber contexts, which are becoming increasingly important to be fluent in. In this way, simply providing access via machines is not enough. There needs to be opportunities for learning about the variety of uses beyond the basic applications which might address the important social inclusion issues that surround digital exclusion. This can often be problematic since new technologies are rapidly evolving and what constitutes digital inclusion changes accordingly. What was considered as advanced three years ago, would now be generally considered as basic to the lives of many citizens. Studies have revealed that the main factors for digital inclusion are relevance, the nature of the experience and empowerment [3]. This basically means that digital experiences have to be connected to the lives and needs of users and will only be perpetuated if they are positive and make life easier for them.

\subsection{The Digital Divide}

The notion of a 'digital divide' came into prominence in around 1996 when then Vice President $\mathrm{Al}$ Gore used it in a speech considering the role of technology in society and highlighted that their use was uneven based on income and status levels. In this way inequalities already in existence in society were being exacerbated by the new technology.

Thus, the digital divide was traditionally described in relation to physical availability of the computer and access to the Internet. Thus it was described as being the difference between the 'haves' and 'have nots'.

\subsection{Digital Inclusion}

The disparity or 'divide' then prompted concerns and action centered around how the divide could be minimized or indeed eliminated and in turn, prompted inquiries and discussions about equity and social justice [4]. Schemes were developed to 'deliver' machines to the disadvantaged but there was not much concern or follow up about how they were used and if the ways in which they were used was productive or not.

Later as DiMaggio and Hargittai stated [5]:

As the technology penetrates into every crevice of society, the pressing question will be not 'who can find a network connection at home work, or in the library or community centre from which to log on?', but instead, 'what are people doing, and what are they able to do, when they go on-line?'

Reconfiguration of the term "access" became the focus of literature that aimed to re-work the idea of the digital divide. According to Warschauer [6] "the simple binary notion of technology haves and have nots does not quite compute" (p.42), in his opinion the key issue is not merely access to computers but rather the unequal ways of using computers. 
It was conceived that the idea of "access" needed to be redefined in social as well as technological terms. Warschauer argues that in order to achieve better outcomes for communities, technology infusion needs to be supported by relevant educational experiences and social support.

DiMaggio and Hargittai [5] highlight the role that society plays in affording all people access to the Internet by noting that the policies of public institutions shape patters of inequality and effective Internet access and use. Everyone can potentially benefit from such policies and thus it becomes increasingly important for public institutions and agencies to consider the issues around access and use of new technologies. Further, As technologies become more pervasive in our lives we also need to provide mechanisms by which assistance can be provided, both formally and informally, so that individuals and groups may participate in online experiences. Formal assistance may include backing from public organizations such as the library or private organizations such as the workplace. Personal assistance is likely to be sought from family, friends and colleagues.

\section{Background}

The initial focus of the Tech Packs project was to identify and distribute computers into low income communities. This took place in Victoria, NSW and Queensland in the first instance and then spread to Western Australia and Tasmania.

Data for this paper is based on most recent phase of the evaluation research from data gathered during 2009 using surveys and focus groups. The surveys consisted of a 'prepack' survey which was developed from the earlier work [7] and in discussions with the Smith Family to identify key themes about the participants. The focus groups were also developed from the pilot study and concentrated on key themes about the benefits and challenges of participating in the project.

We worked with the Smith Family community leaders to distribute surveys to willing participants at the time of initial computer training sessions. At training sessions, prepack surveys were given to willing participants. The surveys were intended to capture data about family demographics, and their perceived computers skills and knowledge prior to the collection of the Tech Packs computer. The first two communities to begin the process in the first half of 2009, they were located in rural areas of two Australian mainland States.

Once a community had completed the prepack surveys, and the Tech Packs computer had been in the home for 4-6 months, focus groups were organised with the respective Smith Family community leaders. This enabled the research to evaluate the use of the computer following its introduction into the home for a good period of time.

\subsection{Children and Families}

Demographic data from this particular cohort revealed that the majority of the Tech Pack participants came from English speaking countries, with most of them being born in Australia. The other most frequently spoken languages were Samoan and Vietnamese. Statistical analysis suggested that most families came from a low-socioeconomic background with education levels not exceeding secondary schooling. A large proportion of survey participants reported as single parents often with children aged 18-24 still living at home. 


\subsection{Survey Data}

A total of 272 surveys were analysed. All surveys were labelled and coded and data was collected and presented using Microsoft Excel. A descriptive statistical analysis was used to report on demographic characteristics and patterns of computer use and computers intentions from the survey participants.

While a significant number of participants said they used digital technologies in a number of different settings, including school, TAFE, work, and at a library, almost two thirds of them had never owned a computer at home. The remaining $27 \%$ of the respondents reported having access to digital hardware components including computers, computer peripherals, such as printers, digital cameras, and scanners as well as to broadband Internet connections in their family home. Current computers usage reported by participants included email and word processing, with one third of the survey sample using computers two to three times a week. Children indicated daily use of new technologies with $93 \%$ of them using computers for school purposes. Children's frequent computer use can be explained by widespread and organised access to computers in schools and public libraries.

Survey results about intended Internet usage also revealed some generational differences, with parents and grandparents wanting to use the computers for communication via email, their own research and study, and for downloading family photos and videos. Consistent with current trends in technology usage by youth, children's intended computer uses included study and research (80\%) as well as the use of social networking applications such as chat rooms and Facebook. Streaming and downloading music was also a popular leisure activity.

User satisfaction when online was significantly limited by the dial-up connectivity. Participants found it difficult to navigate web pages with multimedia content and downloading applications, music or video required spending prolonged periods online. Downloads would frequently be interrupted by incoming calls. As dial-up connection often caused unnecessary frustration, many of participants indicated considering a switch to broadband connectivity.

\subsection{Focus Groups}

Focus groups were conducted with selected community groups from three mainland States. The groups were selected based on their availability for the community leaders to gather a suitable number of participants to a focus group session, the willingness of participants from within the community, and recognition that the community had participated in the prepack surveys.

Smith Family community leaders organised the focus group participants to ensure sufficient numbers at each focus group session. The focus groups concentrated on four major themes including:

- The benefits of having computers at home

- Important changes to daily activities/lifestyle

- Tech Pack support

- Perceived benefits/significance of the program 
The focus groups were all conducted in late 2009. In addition to the participants at each of the focus groups, the Smith Family community leader also attended and participated. The conversations were audio-recorded and transcribed. Transcripts were entered into a data base and were coded and threaded for detailed analysis. This is still occurring with transcripts being finalised with some of the focus group at the time of this interim report (i.e. the Maddington communities).

Findings emerging from the focus groups highlighted that respondents believed in the importance of home computers for learning for their whole family. It became apparent from the data that benefits included making stronger connections between learning in schools and at home for children, having opportunities to engage in new learning, new patterns of intergenerational learning and knowledge transfer based on acknowledging and making use of their children's expertise with new technologies. Both survey and focus group data suggest that children and youth often took lead in installing the Tech Packs at home, helped with technical problems and taught their parents and grandparents valuable technical skills that they needed in order to use the machines. The focus group cases showed how communities indicated that having a computer at home provided children with access to online schoolwork, research, as well as extracurricular activities supported by educational software.

According to focus group participants the training sessions were successful, however, not having access to computers while attending the training appeared to have hindered the acquisition of new skills in the short term. One of the 'weakest' points of the Tech Packs support services appeared to be the under-utilisation of available helpline facilities. Participants reported to be too embarrassed to ask for help, and found it difficult to cope with being put on hold for long periods of time as well as having to explain things several times to a number of people. They stated they would rather turn to family members for help and some of them contacted local business providing technical assistance.

The data from the focus groups revealed a strong correlation between the stated intended use by families and the actual use after several months of having the computers. The most frequent applications were emailing, searching the Internet and participation in online chat sessions. In particular, setting up Facebook accounts was a popular activity for all participants regardless of age.

\section{Summarizing Statements}

In summary the Tech Pack project has been well-received by community members and brought a number of positive changes into their lives. The most significant benefits of the program were increased sense of belonging and social participation for adults, fun and engaging learning for children, access to online community and commercial services, and keeping in touch with family and friends by participating in social networking activities.

Recommendations for improvement to the program include:

1. The adoption of broadband connectivity for all participants

2. Improve the technical specifications of the Tech Packs project with the possible inclusion of a CD burner, and a printer for all communities. Refurbished computers may not be sufficient in terms of adequacy and longevity 
3. Training sessions to be ongoing and community-based to meet the needs of the families and to provide opportunities to extend the skills and knowledge of the participants

4. Utilise existing expertise in the community (e.g. through partnerships with schools, peer-support), to provide participants with more user-friendly technical assistance.

\section{References}

1. Howe, N., Strauss, W.: Millennials rising: The next generation. Vintage, New York (2000)

2. Rideout, V.J., Foehr, U.G., Roberts, D.F.: Generation M2 Media in the lives of 8 to 18 year olds. The Henry Kaiser Family Foundation (2010) (retrieved from

http: / /www.kff.org)

3. Helsper, E.J.: Digital inclusion: An analysis of social disadvantage and the information society. Department for Communities and Local Government (2008),

http: / / www. communities.gov.uk/documents / . . /pdf/digitalinclus ionanalysis

4. Yelland, N.J.: Shift to the future: Rethinking learning with new technologies in education. Routledge, New York (2007)

5. DiMaggio, P., Hargittai, E.C., Celeste, C., Shafer, S.: From Unequal Access to Differentiated Use: A Literature Review and Agenda for Research on Digital Inequality (2001), http: / /www. eszter. com/research/pubs/dimaggio-etaldigitalinequality.pdf

6. Warschauer, M.: Demystifying the digital divide. Scientific American 289(2), 42-47 (2003)

7. Yelland, N.J., Beris, R., Davidson, K., Neal, G.: A computer for every child: Extending contexts for learning for disadvantaged children. International Journal of the Social Sciences 2(4), 503-515 (2007) 